\title{
Genetic Variation among and within United States Collard Cultivars and Landraces as Determined by Randomly Amplified Polymorphic DNA Markers
}

\author{
Mark W. Farnham ${ }^{1}$ \\ U.S. Department of Agriculture, Agricultural Research Service, U.S. Vegetable Laboratory, 2875 \\ Savannah Highway, Charleston, SC 29414-5334
}

\begin{abstract}
Additional index words. cole crops, broccoli, cabbage, Brussels sprouts, cauliflower, Brassica oleracea, RAPD markers
Abstract. A collection of collard (Brassica oleracea $\mathbf{L}$., Acephala group) germplasm, including 13 cultivars or breeding lines and 5 landraces, was evaluated using randomly amplified polymorphic DNA (RAPD) markers and compared to representatives of kale (Acephala group), cabbage (Capitata group), broccoli (Italica group), Brussels sprouts (Gemmifera group), and cauliflower (Botrytis group). Objectives were to assess genetic variation and relationships among collard and other crop entries, evaluate intrapopulation variation of open-pollinated (OP) collard lines, and determine the potential of collard landraces to provide new $B$. oleracea genes. Two hundred nine RAPD bands were scored from 18 oligonucleotide decamer primers when collard and other B. oleracea entries were compared. Of these, $147(70 \%)$ were polymorphic and 29 were specific to collard. Similarity indices between collard entries were computed from RAPD data and these ranged from 0.75 to 0.99 with an average of 0.83 . Collard entries were most closely related to cabbage (similarity index $=0.83$ ) and Brussels sprouts entries (index $=0.80$ ). Analysis of individuals of an OP cultivar and landrace indicated that intrapopulation genetic variance accounts for as much variation as that observed between populations. RAPD analysis identified collard landraces as unique genotypes and showed them to be sources of unique DNA markers. The systematic collection of collard landraces should enhance diversity of the $B$. oleracea germplasm pool and provide genes for future crop improvement.
\end{abstract}

Collard (Brassica oleracea L.) is an important, leafy-green vegetable crop in the southeastern United States. Traditionally, collard is classified in the same botanical group, Acephala, as kale (Hortus Third, 1976). There are about ten cultivars, and five or more breeding lines readily available from commercial or public sources in the United States. Most of these are open-pollinated (OP) lines and the remainder are more recent $F_{1}$ hybrids. Little is known about the genetic makeup of the collard crop and its relationship to the other $B$. oleracea groups such as Italian broccoli or cabbage. There is an additional, generally unrecognized, $B$. oleracea germplasm pool of collard landraces that is being perpetuated by southeastern gardeners and farmers. It is unknown whether these landraces represent unique collard genotypes, and to the author's knowledge there has never been a systematic collection of collard germplasm undertaken in the southeastern United States.

Recent studies of B. oleracea using DNA-based markers including restriction fragment length polymorphisms (RFLPs) and randomly amplified polymorphic DNA (RAPD) markers have provided information regarding 1) the genetic relationships between $B$. oleracea and other related Brassica species (Song et al., 1988a; Song et al., 1988b; Demeke et al., 1992; Ren et al., 1995); 2) the use of DNA-based markers as cultivar or genotype fingerprinting tools (Hu and Quiros, 1991; Kresovich et al., 1992); and 3 ) the diversity existing within the $B$. oleracea germplasm pool (Neinhuis et al., 1993; dos Santos et al., 1994; Kresovich et al.,

Received for publication 16 Aug. 1995. Accepted for publication 10 Jan. 1996. Mention of a trademark, proprietary product, or vendor does not constitute a guarantee or warranty of the product by the U.S. Dept. of Agriculture and does not imply its approval to the exclusion of other products or vendors that might also be suitable. The cost of publishing this paper was defrayed in part by the payment of page charges. Under postal regulations, this paper therefore must be hereby marked advertisement solely to indicate this fact.

${ }^{1}$ Research geneticist.
1992). dos Santos et al. (1994) recently showed that the use of RAPD markers provide a level of resolution equivalent to RFLPs for determination of genetic relationships among $B$. oleracea genotypes. Likewise, Thorman et al. (1994) presented results that indicated RAPD markers give similar information as RFLP data when comparing genetic relationships of individuals within $B$. oleracea as well as within other Brassica species.

Recent molecular marker evaluations of B. oleracea germplasm have provided little information about the collard crop and its relationship to the other crop groups. Song et al. (1988b) included one collard cultivar, 'Georgia', in a study examining genetic relationships between crop groups of $B$. oleracea. In that study the collard entry was more closely related to cabbage representatives than to a kale. However, because Song et al. examined such a small portion of the B. oleracea germplasm pool, they did not draw broad conclusions about genetic relationships among the diverse groups. The present study was undertaken to 1) examine genetic variation among United States collard cultivars and landraces using RAPD markers and determine genetic relationships between different collard lines and also between collard lines and other $B$. oleracea crop representatives; 2) evaluate within line variation of an OP cultivar and an OP landrace; and 3) assess the potential of collard landraces in serving as new sources of collard or B. oleracea genes.

\section{Materials and Methods}

Eighteen entries of collard were obtained for genetic analysis in this study. These entries include 13 named cultivars or breeding lines of collard available from commercial or public sources and an additional five landraces obtained by the author from southeastern gardeners or farmers (Table 1). Although this a limited number of individual lines it is a thorough representation of the commercial collard crop in the United States. In addition to the collard entries, two broccoli, two cabbage, two kale, one cauliflower (Botrytis 
Table 1. Collard and other Brassica oleracea entries compared by RAPD genotyping in this study. Each entry is classified by crop, type of line, and source of seed.

\begin{tabular}{|c|c|c|c|c|}
\hline Entry & Abbreviation & Crop $^{z}$ & Type of line & Source \\
\hline Vates & VA & $\mathrm{Col}$ & OP cultivar & Commercial \\
\hline Morris Heading & MH & $\mathrm{Col}$ & OP cultivar & Commercial \\
\hline Green Glaze & GG & Col & OP cultivar & Commercial \\
\hline Champion & $\mathrm{CH}$ & $\mathrm{Col}$ & OP cultivar & Commercial \\
\hline Georgia & GA & Col & OP cultivar & Commercial \\
\hline Southern & $\mathrm{SO}$ & Col & OP cultivar & Commercial \\
\hline SC Glaze & SG & Col & OP cultivar & Breeder \\
\hline SC Header & SH & Col & OP cultivar & Breeder \\
\hline Top Bunch & TB & Col & $\mathrm{F}_{1}$ hybrid & Commercial \\
\hline Blue Max & $\mathrm{BM}$ & $\mathrm{Col}$ & $\mathrm{F}_{1}$ hybrid & Commercial \\
\hline Flash & FL & Col & $\mathrm{F}_{1}$ hybrid & Commercial \\
\hline Hicrop & $\mathrm{HI}$ & Col & $\mathrm{F}_{1}$ hybrid & Commercial \\
\hline Mezic Zero & MZ & Col & OP landrace & N.C. gardener \\
\hline J. Killough & $\mathrm{JK}$ & Col & OP landrace & Texas gardener \\
\hline J. Hope & $\mathrm{JH}$ & Col & OP landrace & N.C. farmer \\
\hline G. Simpson & SI & Col & OP landrace & N.C. farmer \\
\hline G. Summersett & SU & Col & OP landrace & S.C. gardener \\
\hline Vates kale & VK & Kal & OP cultivar & Commercial \\
\hline Squire & SK & Kal & OP cultivar & Commercial \\
\hline Chas. Wakefield & $\mathrm{CW}$ & $\mathrm{Cab}$ & OP cultivar & Commercial \\
\hline Market Prize & MP & $\mathrm{Cab}$ & $F_{1}$ hybrid & Commercial \\
\hline Atlantic & AT & Bro & OP cultivar & Commercial \\
\hline Packman & PA & Bro & $\mathrm{F}_{1}$ hybrid & Commercial \\
\hline Valiant & VL & Bsp & $F_{1}$ hybrid & Commercial \\
\hline Snow Crown & $\mathrm{SC}$ & $\mathrm{Cau}$ & OP cultivar & Commercial \\
\hline Heavicrop & $\mathrm{HE}$ & Col & $\mathrm{F}_{1}$ hybrid & Commercial \\
\hline
\end{tabular}

${ }^{\mathrm{z}}$ Crop groups abbreviated as $\mathrm{Col}=$ collard, $\mathrm{Kal}=\mathrm{kale}, \mathrm{Cab}=$ cabbage, $\mathrm{Bro}=$ broccoli, $\mathrm{BSP}=\mathrm{Brussels}$ sprouts, and Cau $=$ cauliflower.

group), and one Brussels sprout (Gemmifera group) entries were used for comparison to collard (Table 1). Fifty seed of each entry were sown one seed per cell in a commercial peat mix (Metromix 360, Grace Sierra, Milpitas, Calif.) in 120-cell seedling trays with individual root cell volume of $40 \mathrm{ml}$. Seedlings were grown in a greenhouse 4 Sept. through 7 Oct. 1992 at which time leaves were sampled. Composite leaf samples of each entry were made by combining $0.15 \mathrm{~g}$ of leaf tissue from the youngest leaves from each of 45 seedlings. The composite sample was frozen in liquid $\mathrm{N}_{2}$, ground and mixed in a mortar and pestle, and stored at $-20 \mathrm{C}$ until the tissue was used for DNA extraction. In addition to composite sampling of all entries, leaf samples of 20 individual plants from the collard cultivar 'Morris Heading' and the landrace 'J. Hope' were collected and frozen as described above.

DNA was extracted from $2.0 \mathrm{~g}$ frozen leaf tissue using the CTAB protocol described by Doyle and Doyle (1987), and duplicate extractions were made for each entry. Single plant genomic DNA was similarly extracted from frozen leaves of the individual plants of the 'Morris Heading' and 'J. Hope' collard entries. Final DNA pellets were solubilized in $0.5 \mathrm{ml}$ TE solution, and DNA content of all samples was determined using a DNA fluorometer (model TKO 100; Hoefer Scientific Instruments, San Francisco). Samples were diluted to a working concentration of $12.5 \mathrm{ng} \cdot \mathrm{ml}^{-1}$ with sterile distilled water.

About 30 decamer nucleotide primers, obtained from Operon DNA Technologies (Alameda, Calif.), were screened on a subset of six samples. Eighteen primers, including Operon-designated primers: A02, A03, A04, A05, A07, A17, A18, J05, J19, K12, K14, K18, T01, T08, T11, T15, T16, and T17; that showed consistent banding patterns and amplification were chosen for use in this study. The polymerase chain reaction (PCR) DNA amplification protocol was a variation of that reported by Williams et al. (1990). Reactions were performed in a $25-\mu \mathrm{l}$ volume containing $50 \mathrm{~mm}$ $\mathrm{KCl}, 10 \mathrm{~mm}$ Tris- $\mathrm{HCl}$ (pH 9), $1.5 \mathrm{~mm} \mathrm{MgCl}, 0.01 \%$ gelatin, $0.1 \%$ Triton X-100, 0.2 mm dNTPs, 30 ng oligonucleotide decamer, 50 ng genomic DNA, and 1.0 unit Taq DNA polymerase (Promega, Madison, Wis.). Reactions were run on all duplicate samples. DNA amplification was performed using a thermal cycler (model 480; Perkin-Elmer-Cetus, Norwalk, Conn.). The thermal cycle used was $94 \mathrm{C}$ for $1 \mathrm{~min}$; then 45 cycles of $94 \mathrm{C}$ ( $1 \mathrm{~min}), 35 \mathrm{C}(1 \mathrm{~min})$, and $72 \mathrm{C}(2 \mathrm{~min})$; and finally $72 \mathrm{C}$ for $3 \mathrm{~min}$. A negative control PCR tube containing all components except genomic DNA was included in all thermal cycle runs. RAPD samples were electrophoresed on $1.5 \%$ agarose gels, stained with ethidium bromide and visualized under UV light (Fig. 1). Gels were photographed with black and white film (no. 55; Polaroid, Cambridge, Mass.).

Photographic negatives of duplicate reactions and gels were compared simultaneously. Amplification products of genotypes were scored as present or absent and identified by associate primer number and size in base pairs. Only amplification products that appeared consistently between runs were rated as present in composite scores of entries or individual plants and any bands that were classified as faint were not included in the data set as these were assumed to be unreliable markers. The size of amplification products were determined by comparison to a 100-bp DNA ladder (BRL, Bethesda, Md.) that was run alongside plant samples on every agarose gel.

Statistical analysis was conducted for the 18 collard entries combined with the eight other B. oleracea entries. Each RAPD band across all entries was assigned a number $(1,2,3, \ldots . n)$ and 
each was treated as a unit character coded as 1 (present) or 0 (absent). Genetic similarities were calculated between all pairs of entries based on the following formula: $G S(i j)=S^{N}(i=j) /\left[S^{N}(i=\right.$ $\left.\mathrm{j})+\mathrm{S}^{\mathrm{N}}(\mathrm{i} \neq \mathrm{j})\right]$; which is a simple matching coefficient were GS(ij) is the genetic similarity between entries $i$ and $j, S^{N}(i=j)$ and $S^{N}(i$ $\neq \mathrm{j}$ ) are the total number of concordant and discordant scores between accessions i and j, respectively (Sneath and Sokal, 1973). The complement of GS(ij), the Genetic Distance [GD(ij)], was computed as GD(ij) =1-GS(ij); between all entries. A dendogram was constructed based on the genetic distance matrix data by applying unweighted pair group method with arithmetic averages (UPGMA) cluster analysis using the SAS Proc Cluster program (SAS Institute, Cary, N.C.). An analysis as described above was also performed separately on each population of 20 individuals from each of the two collard entries Morris Heading' and 'J. Hope'.

\section{Results and Discussion}

Twenty-six $B$. oleracea entries, including 18 collard composites were analyzed as a group and a total of 209 RAPD bands were scored. These bands ranged in size from 240 to $2300 \mathrm{bp}$. Between 7 to 16 bands were scored per primer and the average number was 11.5. The number of bands scored per primer for this set of $B$. oleracea entries is within the range observed by others evaluating Brassica germplasm. Hu and Quiros (1991) observed 10 bands per primer, Kresovich et al. (1992) about 8 per primer; and Thorman et al., (1994) 10.5 per primer. A relatively high average number of markers per primer for Brassica species was reported by Ren et al. (1995) who observed over 20 markers per primer. Of the total bands scored in this study, 147 or about $70 \%$ were polymorphic. This percentage of polymorphic bands is very similar to that observed in all of the above-cited studies.

In comparing the $26 \mathrm{~B}$. oleracea entries, a total of 29 RAPD bands were specific to collard. Of that total, 21 bands were unique to at least one collard cultivar or breeding line. The remaining eight bands were specific to at least one of the collard landraces. Similarity indices among collard cultivars and lines ranged from 0.73 to 0.99 with a mean of 0.83 (Table 2). Two pairs of entries, 'Blue Max' and 'HiCrop', and 'Georgia' and 'Southern', had the highest similarity indices of 0.98 and 0.99 , respectively. These two irs represent identical or nearly identical ies or genotypes, and phenotypic observains confirm this (data not shown). The difrences observed between 'Blue Max' and iCrop', both sold as $\mathrm{F}_{1}$ hybrids, may reprent the level of error in genotyping lines with APD markers in this study since all individu; of the hybrids would be expected to be netically identical. Although that may be te with 'Georgia' and 'Southern' as well, it also possible that the slight variations obrved between these two latter, OP populains may be due to variation that exists beeen different lots or sources of these entries. Similarity indices between collard cultirs and landraces ranged from 0.75 to 0.96 , $\mathrm{d}$ the mean index was 0.82 . Although comrison of collard landraces to cultivars indites that the two groups are closely related, no Idrace was exactly like any cultivar. Thus, ch landrace represents a unique collard genose. When collard entries were compared to z other $B$. oleracea entries, collard were und to be most similar to cabbage (mean dex $=0.83$ ) and next to a Brussels sprouts try (mean index $=0.80$ ). In general, collard tries had fewer bands in common with two occoli (mean index $=0.72$ ), one cauliflower tean index $=0.74)$, and two kale (mean index j.73).

Relationships between collard and other sp entries, determined by UPGMA cluster

\footnotetext{
1. RAPD products of collard and other Brassica oleracea ntries generated by primer OPA-05. (A) Resulting gel lectrophoresis and band visualization of composite samples f collard and other entries. The order of samples from left to ight is identical to the order of entries listed in Table 1. Lanes 0 and 20 contain the 100 -bp DNA ladder; darkest band near enteroflaneis $600 \mathrm{bp}$.(B) Resulting profiles of 20 individuals first 20 sample lanes) from the 'Morris Heading' population nd also the composite sample of this cultivar (far right lane). anes 9 and 17 contain the 100-bp DNA ladder.
} 


\begin{tabular}{|c|c|c|c|c|c|c|c|c|c|c|c|c|c|c|c|c|c|c|c|c|c|c|c|c|c|c|}
\hline & \multicolumn{13}{|c|}{ Collard cultivars/lines } & \multicolumn{5}{|c|}{ Collard landraces } & \multicolumn{2}{|c|}{ Kale } & \multicolumn{2}{|c|}{ Cabbage } & \multicolumn{2}{|c|}{ Broccoli } & \multirow{2}{*}{$\begin{array}{l}\text { BS } \\
\text { VL }\end{array}$} & \multirow{2}{*}{$\begin{array}{l}\mathrm{CA} \\
\mathrm{SC}\end{array}$} \\
\hline & VA & MH & GG & $\mathrm{CH}$ & GA & SO & SG & SH & $\mathrm{TB}$ & BM & $\mathrm{HI}$ & FL & $\mathrm{HE}$ & MZ & $\mathrm{JK}$ & JH & SI & SU & VK & SK & $\mathrm{CW}$ & MP & AT & PA & & \\
\hline VA & --- & 87 & 80 & 97 & 86 & 85 & 83 & 90 & 89 & 79 & 78 & 89 & 78 & 82 & 85 & 85 & 84 & 82 & 71 & 72 & 83 & 84 & 72 & 73 & 79 & 75 \\
\hline MH & & --- & 80 & 88 & 86 & 87 & 85 & 85 & 83 & 79 & 78 & 81 & 79 & 79 & 85 & 89 & 83 & 83 & 70 & 72 & 83 & 82 & 69 & 71 & 78 & 72 \\
\hline GG & & & --- & 79 & 79 & 78 & 94 & 79 & 84 & 78 & 78 & 76 & 73 & 78 & 78 & 84 & 82 & 78 & 72 & 76 & 80 & 79 & 72 & 70 & 79 & 74 \\
\hline $\mathrm{CH}$ & & & & --- & 85 & 85 & 83 & 91 & 89 & 80 & 79 & 89 & 87 & 83 & 83 & 85 & 86 & 82 & 73 & 71 & 86 & 85 & 72 & 74 & 82 & 76 \\
\hline GA & & & & & --- & 99 & 83 & 84 & 86 & 82 & 82 & 81 & 81 & 77 & 96 & 90 & 84 & 83 & 71 & 74 & 84 & 86 & 72 & 71 & 79 & 71 \\
\hline SO & & & & & & --- & 83 & 83 & 85 & 83 & 83 & 81 & 80 & 76 & 96 & 90 & 84 & 83 & 71 & 73 & 84 & 86 & 71 & 70 & 79 & 71 \\
\hline SG & & & & & & & --- & 82 & 86 & 83 & 82 & 79 & 77 & 77 & 82 & 86 & 85 & 82 & 75 & 75 & 82 & 83 & 73 & 71 & 80 & 75 \\
\hline $\mathrm{SH}$ & & & & & & & & --- & 88 & 80 & 80 & 86 & 83 & 81 & 83 & 83 & 82 & 80 & 71 & 75 & 83 & 85 & 74 & 74 & 80 & 77 \\
\hline TB & & & & & & & & & --- & 83 & 82 & 84 & 86 & 81 & 84 & 87 & 86 & 84 & 73 & 75 & 85 & 86 & 73 & 72 & 85 & 76 \\
\hline $\mathrm{BM}$ & & & & & & & & & & --- & 98 & 78 & 78 & 72 & 81 & 84 & 80 & 80 & 72 & 71 & 81 & 83 & 73 & 74 & 80 & 75 \\
\hline HI & & & & & & & & & & & --- & 77 & 77 & 83 & 81 & 83 & 79 & 79 & 72 & 82 & 80 & 83 & 71 & 72 & 78 & 74 \\
\hline FL & & & & & & & & & & & & --- & 82 & 81 & 82 & 79 & 78 & 79 & 74 & 73 & 85 & 84 & 73 & 73 & 79 & 77 \\
\hline $\mathrm{HE}$ & & & & & & & & & & & & & --- & 75 & 81 & 78 & 78 & 82 & 70 & 68 & 79 & 81 & 72 & 71 & 77 & 73 \\
\hline $\mathrm{MZ}$ & & & & & & & & & & & & & & --- & 77 & 77 & 80 & 80 & 83 & 82 & 83 & 79 & 76 & 75 & 79 & 75 \\
\hline JK & & & & & & & & & & & & & & & --- & 89 & 82 & 83 & 72 & 75 & 84 & 85 & 72 & 71 & 79 & 72 \\
\hline JH & & & & & & & & & & & & & & & & --- & 92 & 83 & 71 & 71 & 86 & 86 & 70 & 69 & 80 & 73 \\
\hline SI & & & & & & & & & & & & & & & & & --- & 81 & 72 & 70 & 83 & 83 & 70 & 68 & 80 & 74 \\
\hline SU & & & & & & & & & & & & & & & & & & --- & 72 & 72 & 81 & 85 & 70 & 70 & 78 & 73 \\
\hline VK & & & & & & & & & & & & & & & & & & & --- & 90 & 77 & 74 & 70 & 68 & 74 & 67 \\
\hline SK & & & & & & & & & & & & & & & & & & & & --- & 76 & 76 & 74 & 74 & 75 & 70 \\
\hline $\mathrm{CW}$ & & & & & & & & & & & & & & & & & & & & & --- & 92 & 77 & 76 & 83 & 76 \\
\hline MP & & & & & & & & & & & & & & & & & & & & & & --- & 74 & 76 & 82 & 75 \\
\hline $\mathrm{AT}$ & & & & & & & & & & & & & & & & & & & & & & & --- & 93 & 76 & 82 \\
\hline PA & & & & & & & & & & & & & & & & & & & & & & & & --- & 78 & 82 \\
\hline VL & & & & & & & & & & & & & & & & & & & & & & & & & --- & 77 \\
\hline $\mathrm{SC}$ & & & & & & & & & & & & & & & & & & & & & & & & & & --- \\
\hline
\end{tabular}

analysis, are presented in Fig. 2. In general, crop groups fell into distinct clusters. 'Snow Crown' cauliflower clustered independently, but closely, to the two broccoli entries, and the two kale entries clustered together. The one Brussels sprouts entry was also independently clustered as were the two cabbage entries, however, all three of these lines fell into a broad cluster that contained all collard entries. These results are in agreement with those of Song et al. (1988b) who found that one collard entry, among a group of B. oleracea representatives, had a relatively close genetic relationship to cabbage entries.

Within the overall collard cluster, several subclusters were identified (Fig. 2). One subgroup of entries contained a majority of collard cultivars. Two closely related open-pollinating cultivars in this group are 'Vates', one of the most widely grown collard cultivars, and 'Champion', a selection from 'Vates'. A similarity index of 0.97 for these two entries confirms their common genetic background. Three $F_{1}$ hybrids ('Heavicrop', 'Flash', and 'Top Bunch') as well as one breeding line ('SC Header') were also present in this cluster. It would not be unexpected if these entries had 'Vates' in their background, since that line was an industry standard for more than a decade.

A second subgroup of collard contained the open-pollinating line, 'Morris Heading' and two landraces, 'G. Simpson' and 'J. Hope'. The two latter entries were obtained from two different growers in Sampson Co., North Carolina. These two lines, like 'Morris Heading' tend to form a loose head at the main stem apex near the time of crop maturity. Also in this subgroup are the nearly identical entries, 'Georgia' and 'Southern', and also the landrace 'J. Killough'. This landrace had a similarity index of 0.96 between it and the former two cultivars, indicating that it could have been a selection out of those older open-pollinating cultivars.
Two glossy collard entries, 'Green Glaze' and 'SC Glaze' had a similarity index of 0.94 , indicating a relatively similar genetic background, and they did not cluster with a particular group of collard entries. One landrace, 'G. Summersett', also appeared distinct from other collard entries. This line has a very large stature and also tends to form a loose head at maturity. The hybrids, 'Blue Max' and 'HiCrop', also clustered apart from other collard entries.

One collard landrace, 'Mesic Zero' was determined to be more closely related to two kale entries than to any collard. Although the person that saved 'Mesic Zero' called it a collard, it is indeed intermediate in appearance between collard and kale. This landrace exhibits significant plant-to-plant variation; however, most plants have kale-like leaves. It is possible that this line could represent a cross of collard by kale.

Genetic variation within the open-pollinating cultivar 'Morris Heading' and landrace 'J. Hope', as measured by RAPD analysis, was as great as the variation measured among collard composite entries (Table 3). The number of reproducible RAPD markers among 'Morris Heading' individuals was 168 and among 'J. Hope' individuals was 175 . In both populations, about $55 \%$ of the bands were polymorphic. Mean similarity index between individuals of 'Morris Heading' was 0.82 , and between 'J. Hope' individuals was 0.81 . Computation of a similarity index between individuals and the composite sample of each respective population indicated that the magnitude of variation for such comparisons is equal to comparisons between individuals and that no single individual was exactly like the composite. In analyzing individuals for RAPD fingerprints, 13 bands were identified in at least one 'Morris Heading' individual that were not observed in the composite sample or any other collard entry. Likewise, 11 bands were found among 'J. Hope' individuals that were not previously identified. 

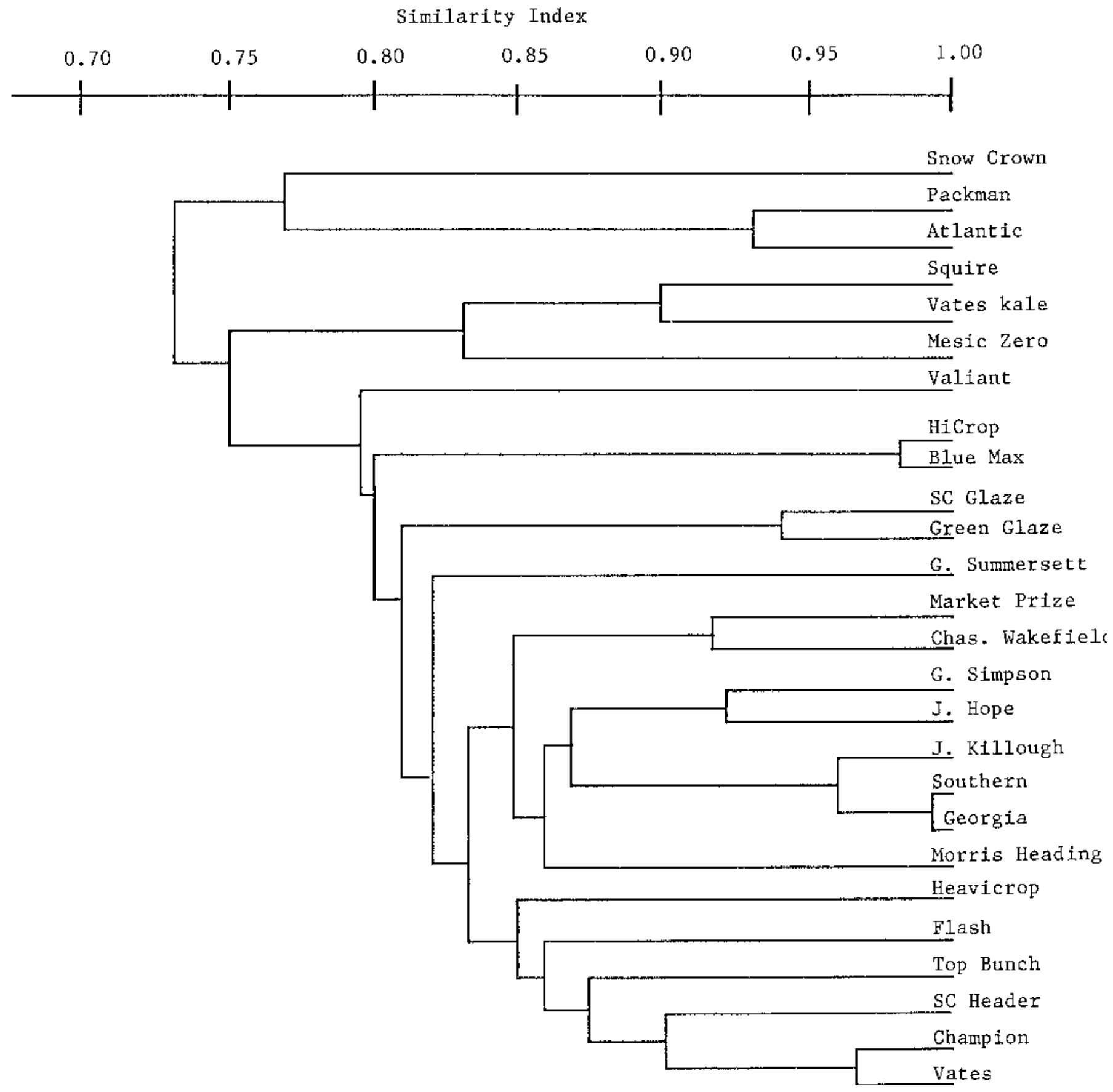

Fig. 2. Dendograph for 26 collard and other Brassica oleracea entries resulting from UPGMA cluster analysis of genetic distances derived from RAPD marker scores. Relationships between entries are quantified using the complementary similarity indices.

These bands were always polymorphic and they usually occurred at low frequencies in the population, at least partially explaining why they were not visible in composite samples. The intrapopulation genetic diversity observed in this study likely contributes a level of diversity to the collard germplasm pool that is of equal significance as the intercultivar or population variation. The author is unaware of other studies of $B$. oleracea where RAPD markers have been used to measure intrapopulation genetic variation. If equal levels of within line variance are found in open-pollinating lines of other crop groups such as cabbage or broccoli, this would represent a greater level of genetic variation previously unrecognized in studies examining only interpopulation genetic differences.

Although collard is officially classified as $B$. oleracea Acephala group, placing it in the same category as the kale crop, observations from this study indicate that collard is more closely related to cabbage (Capitata group). This conclusion is in agreement with that made by Song et al. (1988b) who found a collard individual to be more closely related to cabbage entries than to those of any other $B$. oleracea crop group. Indeed, this conclusion is more intuitively expected since collard has been commonly grown simultaneously with cabbage in the southeastern United States for two to three centuries. On the contrary, kale is a relative newcomer to the Southeast, as little was grown in this region until more recent times. 
Table 3. Genetic similarity indices among individuals of the open-pollinating cultivar 'Morris Heading' and the landrace 'J. Hope'.

\begin{tabular}{lcc}
\hline \hline & \multicolumn{2}{c}{ Population } \\
\cline { 2 - 3 } Index & \multicolumn{2}{c}{ Morris heading } \\
\cline { 2 - 3 } comparison & 0.82 & Jope \\
\hline Mean similarity between individuals & $0.75-0.89$ & 0.81 \\
Range of similarity between individuals & 0.80 & 0.89 \\
Mean similarity between an individual and the composite & $0.76-0.85$ & $0.75-0.85$ \\
Range of similarity between an individual and the composite & \\
\hline
\end{tabular}

of random amplified polymorphic DNA (RAPD): A case study in Brassica. Theor. Appl. Genet. 84:990-994.

Doyle, J.J. and J.L. Doyle. 1987. A rapid DNA isolation procedure for small quantities of fresh leaf tissue. Phytochem. Bul. 19:11-15.

Hortus Third. 1976. Liberty Hyde Bailey hortorium. Macmillan, New York.

$\mathrm{Hu}$, J. and C.F. Quiros. 1991. Identification of broccoli and cauliflower cultivars with RAPD markers. Plant Cell Rpt. 10:505-511.

Several authors (Song et al., 1988b; Williams, 1985) have used the separate crop group label, "Sabellica", to describe the collard group. Although this terminology is not officially recognized (Hortus Third, 1976) or used widely, it may be a reasonable approach to designate the collard as a separate group and to distinguish it from kale. Another approach would be to include collard germplasm as part of the Capitata group. However, a greater number of comparisons between collard and cabbage would be required before concluding that collard germplasm should be classed with the much larger Capitata group.

Collard landraces evaluated in this research represent unique genotypes compared to collard cultivars and breeding lines. RAPD markers specific to the landraces were identified when composite samples of collard cultivars and landraces, as well as cultivars of other cole crops, were compared. Additional unique markers were also uncovered when individuals of OP cultivar and landrace populations were examined. Thus, collard landraces are likely a pool of new genes that might be useful specifically in a collard breeding program, and in general for $B$. oleracea crop improvement. A systematic collection of collard landraces from sources in the southeastern United States should prove a worthwhile endeavor and help to increase the store of $B$. oleracea germplasm adapted to this region.

\section{Literature Cited}

dos Santos, J.B., J. Neinhuis, P. Skroch, J. Tivang, and M.K. Slocum. 1994. Comparison of RAPD and RFLP genetic markers in determining genetic similarity among Brassica oleracea L. genotypes. Theor. Appl. Genet. 87:909-915.

Demeke, T., R.P. Adams, and R. Chibbar. 1992. Potential taxonomic use
Kresovich, S., J.G.K. Williams, J.R. McFerson, E.J. Routman, and B.A. Schaal. 1992. Characterization of genetic identities and relationships of Brassica olerace $\mathrm{L}$. via a random amplified polymorphic DNA assay. 1992. Theor. Appl. Genet. 85:190-196.

Neinhuis, J., M.K. Slocum, D.A. DeVos and R. Mureen. 1993. Genetic similarity among Brassica oleracea L. genotypes as measured by restriction fragment length polymorphisms. J. Amer. Soc. Hort. Sci. 118:298-303.

Ren, J., J.R. McFerson, R. Li, S. Kresovich, W.F. Lamboy. 1995. Identities and relationships among Chinese vegetable Brassicas as determined by random amplified polymorphic DNA markers. J. Amer. Soc. Hort. Sci. 120:548-555.

SAS Institute. 1985. User's guide: Statistics. 5th ed. SAS Institute, Cary, N.C.

Sneath, P.H.A. and R.R. Sokal. 1973. Numerical taxonomy. Freeman, San Francisco.

Song, K.M., T.C. Osborn, and P.H. Williams. 1988a. Brassica taxonomy based on nuclear restriction fragment length polymorphisms (RFLPs) 1. Genome evolution of diploid and amphidiploid species. Theor. Appl. Genet. 75:784-794.

Song, K.M., T.C. Osborn, and P.H. Williams. 1988b. Brassica taxonomy based on nuclear restriction fragment length polymorphisms (RFLPs). II. Preliminary analysis of subspecies within B. rapa (syn. campestris) and B. oleracea. Theor. Appl. Genet. 76:593-600.

Thorman, C.E., M.E. Ferreira, L.E.A. Camargo, J.G. Tivang, and T.C. Osborn. 1994. Comparison of RFLP and RAPD markers to estimating genetic relationships within and among cruciferous species. Theor. Appl. Genet. 88:973-980.

Williams, J.G.K., A.R. Kubelik, K.J. Livak, J.A. Rafalski, and S.V. Tingey. 1990. DNA polymorphisms amplified by arbitrary primers are useful as genetic markers. Nucleic Acids Res. 18:7213-7218.

Williams, P.H. 1985. Crucifer genetics cooperative resource book. Univ. of Wisconsin, Madison, Wis. 